\title{
Superconducting technologies for renewable energy
}

\author{
$K$. Kovalev ${ }^{1}, V$. Poltavets $^{1}$, and $I$. Kolchanova $^{1, *}$ \\ ${ }^{1}$ Moscow Aviation Institute (National Research University), Moscow, Russia
}

\begin{abstract}
The main trends in the development of modern wind-mills are increasing of the output power and efficiency which leds to the increasing of their weight and sizes. The application of high temperature superconducting (HTS) technologies can solve these problems. The article describes of the designs 1 MVA superconducting synchronous generator and 5MJ flywheel energy storage systems (FESS) with HTS magnetic suspension for autonomous wind power engineering.
\end{abstract}

\section{Introduction}

One of the key strategic directions of the world development of electric power industry is to increase its energy efficiency through the introduction of new innovative technologies, including the development of superconducting equipment and its use in power systems. Superconducting materials make it possible to create high-performance devices with a new level of maintenance parameters that can not be achieved using traditional electrical materials.

In recent years leading foreign and Russian scientific centers are working on the creation of wind power plants based on the effect of superconductivity. Hightemperature superconducting (HTS) generators are characterized by higher specific output power, high efficiency, more compact and have an increased resource (see Figure 1). Currently, there are two concepts for designing a superconducting wind turbine generator: fully superconducting machines and partially superconducting machines. In the first case, the rotor and stator windings are superconducting. In the second case, using superconducting wire for the field excitation winding.
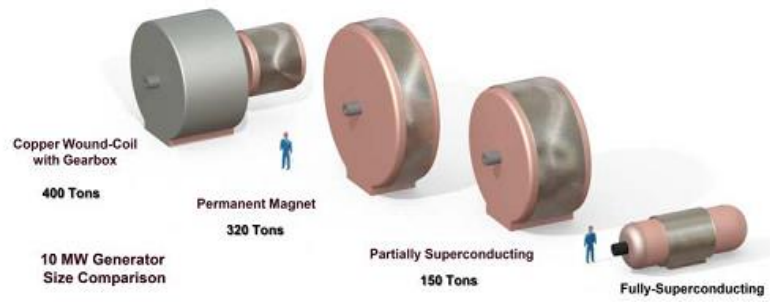

Fig. 1. Comparison designs of $10 \mathrm{MW}$ wind turbine generators [1].

For the manufacture of superconducting windings using the following HTS tapes:

- 1st generation (1G HTS) - compounds based on magnesium diboride $\mathrm{MgB} 2$ and bismuth ceramics in a silver matrix BSCCO, operating at temperatures of liquid hydrogen $(20 \mathrm{~K})$ and neon $(27 \mathrm{~K})$;

- 2nd generation (2G HTS) - compounds based on yttrium ceramics $\mathrm{YBCO}$, operating at a temperature of liquid nitrogen $(77 \mathrm{~K})$.

The main advantage of $2 \mathrm{G}$ HTS tapes is very high magnetic fields and high critical current at liquid nitrogen temperature. The limiting of the critical current in a magnetic field for BSCCO has fundamental reasons (high anisotropy of the electrophysical properties and the associated pinning force of magnetic flux vortices). $\mathrm{MgB} 2$ superconductor is characterized by weak anisotropy of superconducting properties and low cost in comparison with both BSCCO and YBCO, but their use is limited by temperature the hydrogen level $(20 \mathrm{~K})$. The choice of 2 G HTS tapes could lead into a simpler and less costly cooling system compared to $1 \mathrm{G}$ HTS. Table 1 presents a list of projects already created or developed superconducting wind turbine generators.

The main problem of introducing wind power stations (WPS) is the irregularity of their output power. First of all, this is due to the uneven wind speed, which leads to significant fluctuations in power, voltage and frequency of the alternating current of WPS. To ensure stable parameters of electrical voltage and frequency in the network, it is necessary to apply energy storage systems (ESS) using rechargeable batteries (lead-acid, lithium-ion and lithium-polymer) or flywheel energy storage systems (FESS). The main advantages of FESS also include high specific power and high specific density of stored energy, high cycling ability, scalability and modularity. Flywheel systems can work equally well for frequent shallow discharges as well as for very deep discharges.

FESS has been used in power systems for a long time [15]. Primarily they are used in grid companies, and this allows one to smooth the consumption and load peaks, adjust frequency and voltage, and reduce losses at transmission and regulation of reactive power. The most famous developments are that from Beacon Power. These are regulatory plants based on Smart Energy

*Corresponding author: kira_310@mail.ru 
Table 1. Superconducting wind turbine generators.

\begin{tabular}{|c|c|c|c|c|c|}
\hline Year to reach & $\begin{array}{l}\text { Power } \\
\text { (MW) }\end{array}$ & $\begin{array}{l}\text { Speed } \\
(\mathrm{rpm})\end{array}$ & $\begin{array}{c}\text { Conductor } \\
\text { type }\end{array}$ & $\begin{array}{l}\text { Cryogenic } \\
\text { cooling }\end{array}$ & Company/Project \\
\hline 2010 & 0.5 & 30 & BSCCO & & Converteam \\
\hline 2012 & 1 & 500 & $\mathrm{BSCCO}$ & $\mathrm{LN}_{2}$ & $\begin{array}{c}\text { Wuhan Institute of Marine Electric Propulsion } \\
{[2]}\end{array}$ \\
\hline $2009-2013$ & 1.79 & 214 & $\mathrm{BSCCO}$ & $\mathrm{GHe}$ & Converteam (Hydro-Genie) [3] \\
\hline $2011-2015$ & 1 & 600 & YBCO & $\mathrm{LN}_{2}$ & MAI [4] \\
\hline 2015 & 3.6 & 15 & $\mathrm{YBCO}$ & & Envision (EcoSwing) [5] \\
\hline \multirow[t]{10}{*}{$2009-2016$} & 0.5 & & $\mathrm{MgB}_{2}$ & $\mathrm{GHe}$ & Technalia [6] \\
\hline & 10 & 8 & $\mathrm{MgB}_{2}$ & $\mathrm{GHe}$ & Technalia [6] \\
\hline & 10 & 10 & (RE)BCO & $\mathrm{GHe}$ & AIST/Furukawa Electric [7] \\
\hline & 8 & 11 & $\mathrm{YBCO}$ & $\mathrm{LN}_{2}$ & AMSC/TECO [8] \\
\hline & 12 & 10 & YBCO & $\mathrm{GHe}$ & Changwon National Univ. [9] \\
\hline & 10 & 10 & YBCO & & GE [10] \\
\hline & 8 & 12 & YBCO & $\mathrm{GHe}$ & GE/ Converteam [11] \\
\hline & 10 & 8 & YBCO & $\mathrm{GHe}$ & Converteam [12] \\
\hline & 10 & 10 & $\mathrm{MgB}_{2}$ & $\mathrm{GHe}$ & Kalsi Green power system [13] \\
\hline & 10 & 10 & YBCO & & Tokyo Univ. of Marine Sci.\& Tech. [14] \\
\hline
\end{tabular}

Matrix 0.5 MW (Tyngsboro, MA), 20 MW (Stephentown, NY) and $20 \mathrm{MW}$ (Hazle, PA) complexes [16]. FESS is successfully used in MicroGrid to stabilize the network with renewable energy sources (RES). The leading positions in this direction are occupied by $\mathrm{ABB}$ [17-19].

The latest achievements in the field of technology of superconducting passive magnetic bearings and their application in the design of the FESS can increase the working life (more than 15 years) of the drive, creating environmentally friendly energy storage systems with a long shelf life of stored energy.

\section{Superconducting generator for wind turbines}

In 2015 MAI jointly with the leading Russian research centers (JSC «NIIEM», NRC «Kurchatov Institute»IHEP, Protvino) created and tested first of Russia 1 MVA high-temperature superconducting synchronous generator (HTSSG-1000) with HTS $2 \mathrm{G}$ field windings cooled with liquid nitrogen [6]. This work was carried in the framework of implementation of the Rosatom atomic energy state corporation Innovative Energy/Superconducting Industry project (2011-2015). Photo of the prototype HTS wind generator during the bench tests is shown in Figure 2. Table 2 lists main parameters of 1 MVA HTS generator.

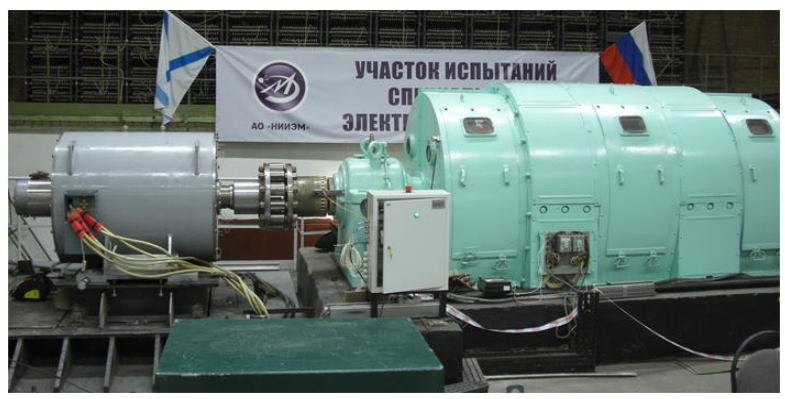

Fig. 2. 1 MVA prototype HTS wind generator (left) with drive motor (right) on the test bench.
Table 2. Main parameters of 1 MVA synchronous 2 G HTS generator

\begin{tabular}{|l|c|}
\hline \multicolumn{1}{|c|}{ List of parameters, units } & Value \\
\hline Nominal output power, $\mathrm{kVA}$ & 1000 \\
\hline Phase voltage, $\mathrm{V}$ & 690 \\
\hline Nominal speed, rpm & 600 \\
\hline Rated electrical frequency, $\mathrm{Hz}$ & 50 \\
\hline Nominal torque, Nm & 16000 \\
\hline Nominal current, $\mathrm{A}$ & 500 \\
\hline Number of poles & 10 \\
\hline Number of phases & 3 \\
\hline Inner diameter of the stator, mm & 800 \\
\hline Active light, mm & 400 \\
\hline Field winding type & $\mathrm{HTS} 2 \mathrm{G}$ tape \\
\hline Coil shape & Racetrack \\
\hline Cryogenic cooling & $\mathrm{LN} 2$ \\
\hline Armature winding type & $\mathrm{Cu}$ \\
\hline Stator coolant & $\mathrm{Water}$ \\
\hline Weight, $\mathrm{t}$ & 4.2 \\
\hline $\begin{array}{l}\text { Full load efficiency (without the } \\
\text { cryocooler), } \%\end{array}$ & 98.6 \\
\hline
\end{tabular}

Stator HTSSG-1000 is made according to the classical scheme with copper windings. The stator with 120 slots made of the electrotechnical steel sheets with the thickness of $0.35 \mathrm{~mm}$. The thermal calculation of the geometric model HTSSG showed the need for forced cooling of the stator. As a result, the stator is water cooled through cooling channels in the housing.

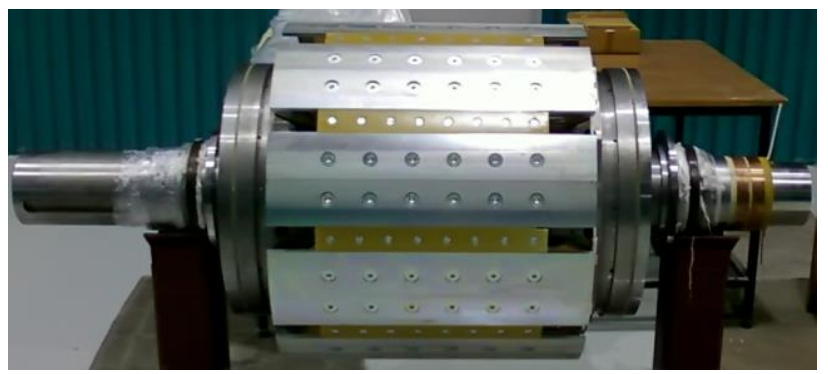

Fig. 3. Rotor HTSSG-1000 assembly (without cryostat), 
The HTS rotor is an explicit pole structure. Salient pole ferromagnetic rotor with HTS field excitation winding consist 10 poles (see Figure 3). The rotor poles are manufactured separately and then installed on the magnetic core. Between the poles there are wedges made of fiberglass (see Figure 4), which together with the pole tips form a cylindrical surface.

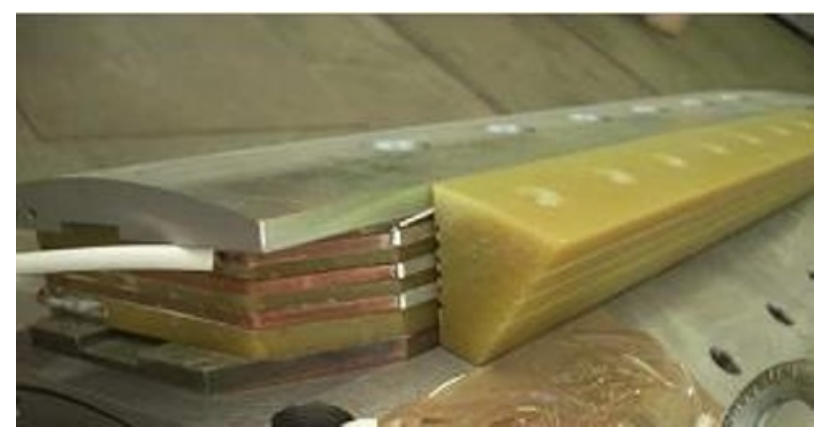

Fig. 4. YBCO coil and ferromagnetic pole shoe installed on the ferromagnetic rotor yoke.

When choosing the type of HTS coils were taken into account features of HTS $2 \mathrm{G}$ tape. These are limitation of the bending radius of the tape, no possibility of bending on the edge, low mechanical strength. To create a superconducting excitation winding HTSSG-1000, the racetrack type coil was selected (Figure 5). This design is modular and each individual module is mounted on the magnetic core.

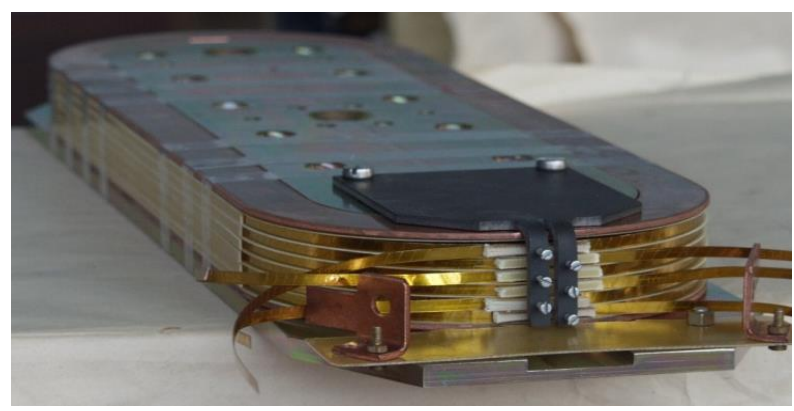

Fig. 5. YBCO coil.

The rotor HTSSG is a rotating cryostat carrying an HTS winding consisting of racetrack modules. The HTS coils are cooled with liquid nitrogen, which circulates through channels in the pole and wedges. The total length of HTS tape (AMSC - Amperium ${ }^{\mathrm{TM}}$, dimensions are $4.93 \times(0.32-0.40) \mathrm{mm}^{2}$.) for field coils that has been used is about $5.2 \mathrm{~km} \mathrm{[4].}$

The operating temperature of the superconducting excitation winding of the rotor at the level of $65-75 \mathrm{~K}$ for 10,000 hours (the life of the continuous operation of the HTSSG-1000 in the windmill) is provided by an autonomous system of cryogenic support using the Turbo-Brighton cycle with a cooling power of $2.5 \mathrm{~kW}$ (see Figure 6). This cryogenic system was specially designed and manufactured at MAI. This type of cryogenic systems provides a large overhaul interval (over 30000 hours) with high efficiency.

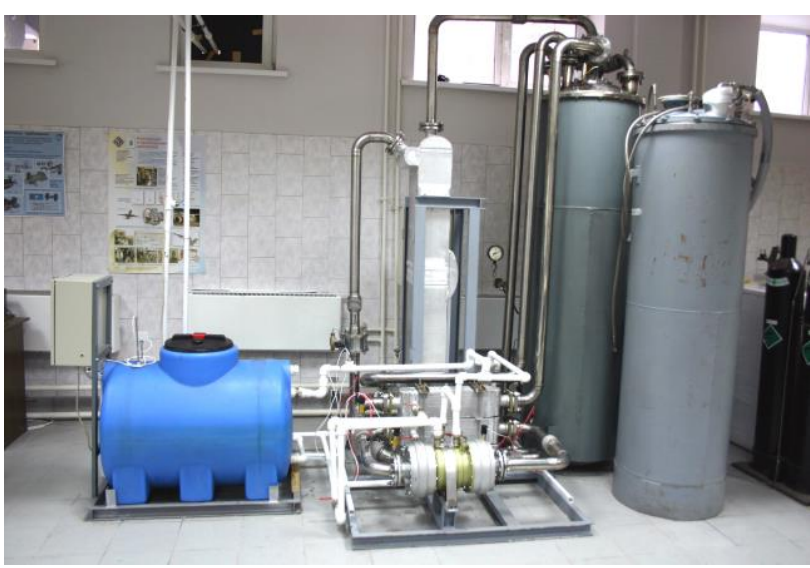

Fig. 6. General view of cryogenics cooling system.

\section{Flywheel energy storage systems with magnetic HTS suspension for autonomous wind power stations}

In 2015 MAI jointly with the Bauman Moscow State Technical University, MBDB "Horizont", JSC "VPO Tochmash", "Centrotech-SPb and JSC "NIIEM" created and tested 5 MJ FESS prototype with magnetic HTS suspension. This work have been similarly carried in the framework of implementation of the Rosatom atomic energy state corporation Innovative Energy/Superconducting Industry project (2011-2015) $[20,21]$. Table 3 lists main parameters of the $5 \mathrm{MJ}$ FESS.

Table 3. Main parameters of the prototype FESS

\begin{tabular}{|c|c|}
\hline List of parameters, units & Value \\
\hline Stored energy, MJ & 5 \\
\hline Output power, kW & 100 \\
\hline Supply voltage frequency, Hz & $300-400$ \\
\hline Output voltage range, V & $150-350$ \\
\hline Frequency using the inverter, Hz & 50 \\
\hline Nominal charging time, sec & 300 \\
\hline Minimum discharge time, sec & 50 \\
\hline Maximum rotation speed, rpm & 8000 \\
\hline
\end{tabular}

The main structural elements of FESS are: flywheel, motor generator, upper and lower magnetic HTS suspension, magnetic bearing on permanent magnets (PM) and mobile lower bearing. Photo of the prototype FESS with a magnetic HTS suspension during the bench tests is shown in Figure 7. The flywheel rotor of the 5 MJ FESS (Figure 8) has a multi-layer construction (D16 aluminum alloy disc, stainless steel pipe and carbon fiber bandage). Such flywheels are more reliable and safer in operation than solid metal flywheels.

The FESS rotating assembly is supported by a levitation system consisting of a magnetic support and two cylindrical magnetic HTS suspensions located in the upper and lower parts of the flywheel shaft. Magnetic support keeps the flywheel axially, and magnetic HTS suspensions provide radial stability and partial compensation of the flywheel's weight. The magnetic 
support is made on the basis of counter-magnetized conical ring permanent magnets (PM) of trapezoidal section made from $\mathrm{NdFeB}$.

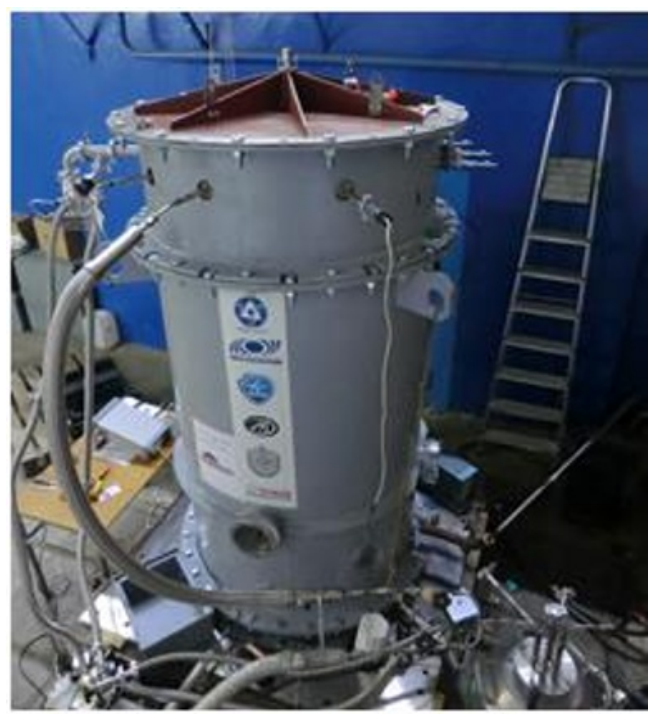

Fig. 7. 5MJ FESS with magnetic HTS suspension during the bench tests.

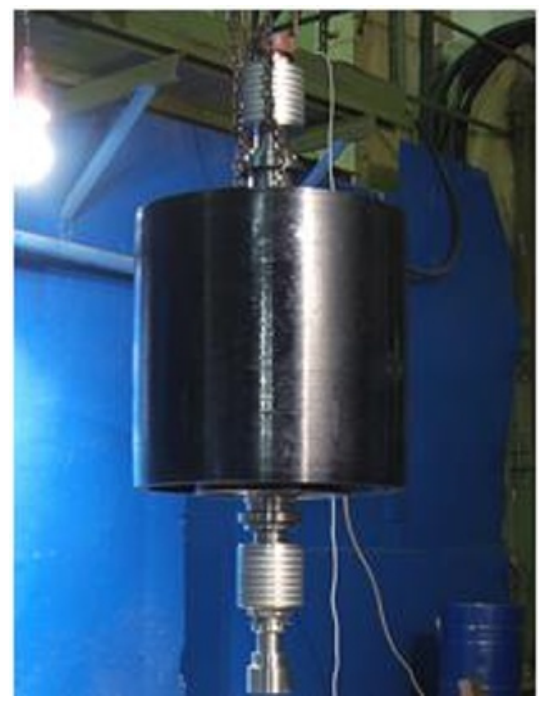

Fig. 8. The flywheel rotor with rotors (upper and lower) of magnetic HTS suspensions.

The main elements of HTS suspensions are stator and rotor (Figure 9). The magnetic suspension stator (Figure 9b) contains a block with HTS elements based on yttrium ceramics (YBCO). The rotor of the magnetic HTS suspension (Figure 9c) consists of magnetic rings made of $\mathrm{NdFeB}$, which are arranged along the axis and connected by a liner. Spacers made of magnetically soft material are located between the magnets, which provide formation of the necessary structure of magnetic field in the gap between the rotor and the stator.

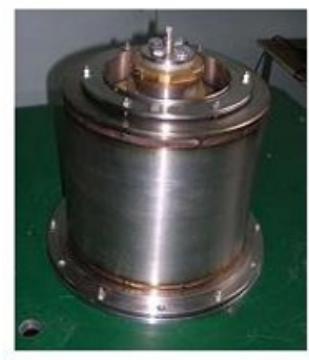

a

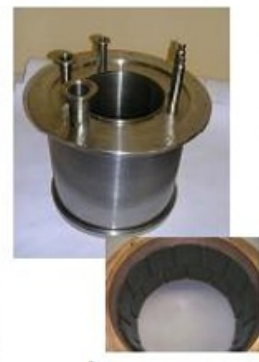

Fig. 9. Assembly of magnetic HTS suspension: a - the lower HTS suspension; $b$ - stator of lower HTS suspension with HTS unit; c - rotor.

This 5 MJ FESS employed a motor/generator with a rated power of $100 \mathrm{~kW}$. Structurally, it is a three-phase six-pole electric machine with $\mathrm{PM}$ made of $\mathrm{NdFeB}$ with radial-tangential magnetization and an ironless stator. The motor/generator was designed by MAI. The stator of the motor/generator is shown in Figure 10.

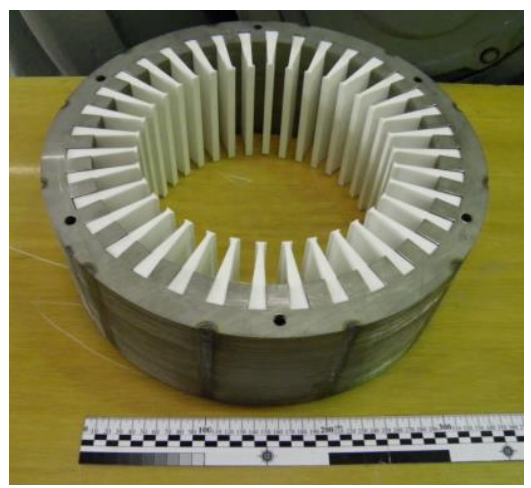

Fig. 10. The stator of the motor/generator.

\section{Conclusions}

Works on creation of prototypes 1 MVA synchronous 2G HTS generator and 5 MJ FESS with a magnetic HTS suspension are been successfully completed.

Technical and economic effect of the use of superconducting analogues of existing generators of wind turbines at the same electrical power is expressed in a significant reduction in size and weight, which reduces costs and reduces the time of manufacture and installation of wind turbines.

The economic effect of the introduction of superconducting FESS in autonomous wind power system (AWPS) is achieved by increasing the reliability and stability of the energy system, improving the quality of electricity to supply consumers. The use of magnetic HTS bearings allows to increase the working life (more than 15 years) of the drive, creating environmentally friendly energy storage systems with a long shelf life of stored energy. Recent advances in the technology of production of composite materials and their use for the manufacture of flywheels makes such a flywheel quite reliable and safe, allowing to significantly increase the speed of rotation of the flywheel, and consequently the energy consumption of the accumulation system. 
Thus, the use of superconducting electrical equipment as part of AWPS will reduce capital costs, improve overall efficiency by reducing losses in the generation, conversion and distribution of energy, as well as increase the level of fire and environmental safety.

\section{References}

[1] D. Kostopoulos, D. Liu, H. Polinder, Feasibility study of $10 \mathrm{MW} \mathrm{MgB2}$ fully superconducting generator for offshore wind turbines Conference Paper. EWEA Offshore Conference. (2013)

[2] Z. Jun, X. Feng, C. Wei, D. Yijun, C. Jin, T. Wenbin, The Study and Test for 1MW High Temperature Superconducting Motor IEEE/CSC \& ESAS EUROPEAN SUPERCONDUCTIVITY NEWS FORUM, 22, October/November 2012. IEEE Trans. Appl. Supercond. (2013)

[3] P. Tixador, Development of superconducting power devices in Europe Physica C: Superconductivity, 470(20), 971-79 (2010)

[4] K. Kovalev, V. Poltavets, I. Kolchanova, R. Ilyasov, V. Firsov, 1MVA HTS Generator for wind turbines Theoretical and scientific-practical journal ELECTRICHESTVO, 10, 4-16 (2017)

[5] M. Bauer, EcoSwing superconducting wind power generator International Superconductivity Industry Summit, 27, 1-36 (2018)

[6] I. Marino, A. Pujana, G. Sarmiento, S. Sanz, J.M. Merino, M. Tropeano, J. Sun, T. Canosa, Lightweight $\mathrm{MgB} 2$ superconducting $10 \mathrm{MW}$ wind generator Supercond. Sci. Technol. 29 024005, 11 (2016)

[7] S. Fukui, J. Ogawa, T. Sato, S. Nagaya, Study of $10 \mathrm{MW}$-Class wind turbine synchronous generators with HTS field windings IEEE Trans. Appl. Supercond. 21(3), 1151-54(2011)

[8] H. Karmaker, et al Stator design concepts for an $8 \mathrm{MW}$ direct drive superconducting wind generator Proc. of the Int. Conf. on Electrical Machines 769-74 (2012)

[9] H.J. Sung, Choi J., R.A. Badcock, Z. Jiang, M. Park, I.K. Yu, Design and heat load analysis of a $12 \mathrm{MW}$ HTS wind power generator module employing a brushless HTS exciter IEEE Transactions on Appl. Superconductivity 26(1), doi:10.1109/tasc.2016.2543838 (2016)

[10] R. Fair, et al Superconductivity for large scale wind turbines DOE/EE0005143. General Electric-Global Research (2012)

[11] C. Lewis, J. Muller, A direct drive wind turbine HTS generator IEEE Power Eng. Soc. Gen. Meeting 24, $1-8$ (2007)

[12] H. Karmaker, et al Design concepts for a direct drive wind generator using new superconductors Proc. of the EPEC 22-25 (2015)

[13] S.S. Kalsi, Superconducting wind turbine generator employing MgB2 windings both on rotor and stator. IEEE Transactions on Appl. Superconductivity 24(1), 47-53 (2014)

[14] W. Xu, N. Maki, M. Izumi, Operation temperature influence on performance of $10 \mathrm{MW}$ wind turbine HTS generators IEEE Transactions on Appl. Superconductivity 25(3), 1-4 (2015)

[15] M.A. Awadallah, B. Venkatesh, Energy Storage in Flywheels: An Overview. Canadian J. of Electrical and Computer Engineering 38(2), 183-193 (2015)

[16] Forbes Beacon Power to Build a Flywheel Plant to Keep the Grid in Good Health. 18 June 2015 Available online: http://www.forbes.com/ (2015)

[17] W. Galton, Stabilizing and maximizing renewables using a flywheel-inverter system. RPI CFES Workshop on Microgrid Technology and Applications: ABB, (2013)

[18] S. Cleiton, Renewable microgrids Reduced LCOE and secured supply (2016)

[19] ABB Microgrid Solutions. Worldwide Installations. Local Grids Management Systems Workshop (2015)

[20] V. Poltavets, K. Kovalev, R. Ilyasov, A. Glazunov, V. Maevsky, L. Verzbitsky, V. Akhmadyshev, A. Shikov, 5 MJ flywheel based on bulk HTS magnetic suspension. 11th European Conf. on Appl. Superconductivity (EUCAS2013). J. of Phys: Conference Series 032022, 507(2014)

[21] V. Poltavets, K. Kovalev, I. Kolchanova, R. Ilyasov, Int. Conf. on Fundamental problems of high temperature superconductivity. The workbook of the extended abstracts 240-241 (2015) 